\title{
Role of S100B Serum Concentration as a Surrogate Outcome Parameter After Mechanical Thrombectomy
}

Sebastian Luger, MD, Kimberly Koerbel, MD, Ariane Martinez Oeckel, MD, Hauke Schneider, MD, MBA, Christoph J. Maurer, MD, Gudrun Hintereder, MD, Marlies Wagner, MD, Elke Hattingen, MD, and

Christian Foerch, MD

Neurology ${ }^{\circledR}$ 2021;97:e2185-e2194. doi:10.1212/WNL.0000000000012918

\author{
Correspondence \\ Dr. Luger \\ Sebastian.Luger@kgu.de
}

\begin{abstract}
\section{Background and Objectives}

To establish serum concentration of protein S100B as an objective biomarker surrogate for astroglial tissue damage after mechanical thrombectomy in patients with acute ischemic stroke.
\end{abstract}

\section{Methods}

This prospective 2-center study recruited patients with acute middle cerebral artery infarctions caused by large vessel occlusion treated with mechanical thrombectomy. Blood samples were collected at day 2 after intervention and analyzed for S100B serum concentrations using ELISA techniques. Infarct size was determined on follow-up brain imaging and functional outcome according to modified Rankin Scale (mRS) was assessed at 90 days.

\section{Results}

A total of 171 patients were included (mean age \pm SD: $70 \pm 14$ years, $42 \%$ female). S100B levels correlated with infarct size. Median S100B concentrations at day 2 after intervention were lower in patients with favorable outcome (mRS score 0-1) at 90 days compared to patients with unfavorable outcome (mRS score 2-6) (median $0.10 \mu \mathrm{g} / \mathrm{L}$ [interquartile range $0.07-0.14$ ] vs $0.20 \mu \mathrm{g} / \mathrm{L}[0.11-0.48], p<0.001$ ). Younger age (odds ratio [OR] 1.120 [confidence interval (CI) 1.068-1.174]; $p<0.001$ ), lower National Institutes of Health Stroke Scale score 24 hours after symptom onset (OR 1.232 [CI 1.106-1.372]; $p<0.001$ ), and lower S100B serum concentrations (OR 1.364 [CI 1.105-1.683]; $p=0.004$ ) were independently associated with a favorable outcome. S100B was able to eliminate the lateralization bias associated with the use of $\mathrm{mRS}$ for functional outcome assessment at 90 days after stroke.

\section{Discussion}

S100B serum concentrations after mechanical thrombectomy indicate the extent of ischemic tissue damage. This can be assessed rapidly, independent of brain imaging and clinical outcome scales. Following prospective validation in further studies, this may provide an objective surrogate outcome measure both in clinical routine and interventional trials.

\section{Classification of Evidence}

This study provides Class I evidence that S100B 2 days following mechanical thrombectomy for acute ischemic stroke accurately distinguishes favorable from unfavorable functional outcome.
MORE ONLINE

III Class of Evidence

Criteria for rating

therapeutic and diagnostic studies

NPub.org/coe

From the Department of Neurology (S.L., K.K., A.M.O., C.F.), Central Laboratory (G.H.), and Institute of Neuroradiology (M.W., E.H.), University Hospital Frankfurt / Goethe University Frankfurt; and Departments of Neurology (H.S.) and Diagnostic and Interventional Radiology and Neuroradiology (C.J.M.), University Hospital Augsburg, Germany.

Go to Neurology.org/N for full disclosures. Funding information and disclosures deemed relevant by the authors, if any, are provided at the end of the article. 


\section{Glossary}

ASPECTS = Alberta Stroke Program Early CT Score; CI = confidence interval; CTA = CT angiography; IQR = interquartile range; $\mathbf{L V O}=$ large vessel occlusion; $\mathbf{M C A}=$ middle cerebral artery; $\mathbf{M R A}=$ magnetic resonance angiography; $\mathbf{m R S}=$ modified Rankin Scale; $\mathbf{M T}=$ mechanical thrombectomy; $\mathbf{m T I C I}=$ modified Thrombolysis in Cerebral Infarction; NIHSS = National Institutes of Health Stroke Scale; OR = odds ratio.

Mechanical thrombectomy (MT) is a highly effective treatment for patients with large artery occlusive stroke. Evidence was generated by randomized controlled trials evaluating both established and extended time windows. ${ }^{1,2}$ All of these studies used the modified Rankin scale (mRS) at 90 days for primary outcome assessment. ${ }^{3,4}$ However, the reliability of such crude outcome scales is frequently questioned in the literature, among others due to significant interrater variability ${ }^{5-7}$ and lateralization bias $^{8,9}$ induced by hemispheric-specific occurrence of neurologic deficits. In the nondominant hemisphere, even larger supratentorial infarcts may not necessarily translate into measurable disability (in terms of the mRS), but subtle neuropsychological changes may persist, hampering patients' quality of life in the long run. ${ }^{10,11}$ In the dominant hemisphere, even smaller infarcts in eloquent locations may cause severe aphasia, hampering rehabilitation prognosis and increasing long-term disability.

A rapidly available and objective surrogate endpoint measure providing information on the extent of tissue damage following ischemic stroke and MT would be a valuable adjunct to the functional outcome determined by mRS. ${ }^{12}$ Notably, final infarct volume on follow-up brain imaging is not commonly used as a surrogate measure. Its reliable determination requires advanced imaging processing tools to cover the patchy infarct zones resulting from thrombus fragmentation and to deal with the subtle changes of signal intensity at the borders of the ischemic core on T2 and fluid-attenuated inversion recovery sequences. ${ }^{13}$

The astroglial protein S100B has been investigated in patients with ischemic stroke for many years. S100B serum concentrations measured 48-72 hours after symptom onset are highly correlated to final infarct volume (i.e., the ischemic core) and functional outcome. ${ }^{14-17}$ Moreover, studies demonstrated that successful recanalization of large vessel occlusion (LVO) (i.e., without evidence of demarcated infarcts on follow-up brain imaging) does not result in astroglial protein (S100B, GFAP) elevation in the bloodstream. ${ }^{18,19}$ In other words, S100B is an indicator of the extent of the ischemic core (i.e., astroglial tissue damage on a cellular level), but not of transient perfusion deficits, even in case of LVO. This makes S100B an ideal surrogate outcome biomarker for patients with ischemic stroke who undergo MT.

The aim of this study was to establish S100B serum concentrations at day 2 after mechanical recanalization as an objective surrogate indicating the amount of astroglial tissue damage. Potential applications comprise the prediction of functional outcome in individual stroke cases (separated for the left and right hemisphere) as well as its use as a monitoring measure for tissue outcome in clinical trials and in quality assurance processes.

\section{Methods}

\section{Study Design and Study Centers}

The Biomarker for Prediction of Outcome After Mechanical Thrombectomy in Acute Ischemic Stroke Study (BE PROMETHEUS) was designed as a 2-center prospective trial conducted at the Department of Neurology, GoetheUniversity Hospital, Frankfurt am Main, Germany, and the Department of Neurology, University Hospital, Augsburg, Germany. Both centers are members of IGNITE (Initiative for German NeuroIntensive Trial Engagement). ${ }^{20}$

\section{Standard Protocol Approvals, Registrations, and Patient Consents}

The institutional review boards of both centers approved the study protocol on human experimentation (242-17). The study has been performed in accordance with the ethical standards as laid down in the 1964 Declaration of Helsinki and its later amendments. It followed the guidelines for reporting observational studies (STROBE). ${ }^{21}$ Written informed consent for study participation was obtained from patients or their legal representatives (after MT, but before blood sampling).

\section{Data Availability}

Anonymized data used in this study are available on request from Dr. Luger.

\section{Sample Size Calculation}

Our study was designed to provide Class I evidence regarding the value of S100B on day 2 after MT in predicting functional outcome at 90 days. Based on previous investigations in patients with stroke with LVO receiving IV thrombolysis, ${ }^{18}$ we assumed S100B serum concentrations on day 2 after MT to be lower in patients with successful vessel recanalization as compared to patients with persistent vessel occlusion. Furthermore, based on randomized clinical trials, we assumed a ratio between patients with a favorable (mRS $0-1)$ and an unfavorable functional outcome at 90 days of 1:2. ${ }^{1}$ Thus, sample size calculation (clincalc.com) was based on the following measures: mean S100B in mRS 2-6: $1.0+1.2 \mu \mathrm{g} / \mathrm{L}$, mean S100B in mRS 0-1: $0.4 \mu \mathrm{g} / \mathrm{L}$, enrollment ratio 0.5, a 
0.05 , power $80 \%$. This resulted in a sample size of at least 141 patients. In total, 171 patients were recruited.

\section{Inclusion of Patients}

All consecutive patients admitted to the study centers with an acute middle cerebral artery (MCA) infarction caused by LVO (i.e., carotid T, M1, or M2 branch) scheduled to undergo endovascular stroke treatment were screened (at Frankfurt University between January 2017 and October 2019; at Augsburg University between March 2019 and October 2019). The indication to perform MT was based on current clinical guidelines. ${ }^{22}$ MT was performed with a balloon guide catheter and stent retriever (Solitaire Revascularization Device). Alternatively, distal intermediate and aspiration catheters were used in combination with a stent retriever. Exclusion criteria were (1) age below 18 years, (2) any stroke or TIA within the last 3 months, (3) known malignant melanoma in medical history, (4) traumatic brain injury within the last 3 months (including head concussion at onset of symptoms). Traumatic brain injury and malignant melanoma increase serum concentrations of S100B. ${ }^{23,24}$

\section{Clinical Measures}

The following clinical baseline variables were collected: age, sex, mRS before admission, information on previous diseases and vascular risk factors, National Institutes of Health Stroke Scale (NIHSS) at admission and at 24 hours, the Alberta Stroke Program Early CT Score (ASPECTS) based on initial, pretreatment brain imaging, radiologic classification of vessel occlusion based on first diagnostic angiography (i.e., CT angiography [CTA] or magnetic resonance angiography [MRA] prior to any intervention), thrombolytic therapy, recanalization status after MT (modified Thrombolysis in Cerebral Infarction [mTICI] classification ${ }^{25}$ ), and stroke etiology according to TOAST (Trial of Org 10172 in Acute Stroke Treatment) classification. ${ }^{26}$ Three months after discharge from the acute hospital treatment, a standardized telephone interview was conducted with each patient or next of kin to determine the current mRS. ${ }^{27}$

\section{Blood Sampling and S100B Measurement}

Previous studies reported a steady increase of S100B values after ischemic stroke onset with maximum values observed between 48 and 72 hours. The timepoint 48 hours emerged as best predictive for final infarct volume and functional outcome. $^{14-17}$ For our study, at day 2 after MT, a venous blood sample was drawn using serum tubes with clot activator (S-Monovette, $4.7 \mathrm{~mL}$, Sarstedt). Blood samples were delivered to the laboratory at the respective study center for centrifugation within 2 hours after collection. Serum was pipetted in $0.5 \mathrm{~mL}$ aliquots and frozen down, first at $-20^{\circ} \mathrm{C}$ and then moved to $-80^{\circ} \mathrm{C}$ for long-term storage until analysis. A temperature-controlled transport on dry ice was later used for shipment for the samples from Augsburg to Frankfurt am Main, where all samples were measured at a single time point.

The determination of the biomarker S100B was performed at the central laboratory of the University Hospital Frankfurt am
Main via an approved and commercially available electrochemiluminescence S100B immunoassay (ECLIA; Elecsys S100, Roche Diagnostics Deutschland $\mathrm{GmbH}){ }^{28}$ This ECLIA works as a sandwich immunoassay with Ruthenium(II)-tris (bipyridyl) conjugated antibodies. The targeted protein S100B forms a complex with free and fixed antibodies so that the serum concentration correlates with the number of Ruthenium complexes. In a following redox reaction, photons are emitted under consumption of tripropylamine. The emerging light with a wavelength of $620 \mathrm{~nm}$ is registered and summated. Serum samples were processed and assayed by laboratory technicians who were blinded to all clinical information. The technical details are as follows: lower limit of detection $0.005 \mu \mathrm{g} / \mathrm{L}$, measuring range $0.005-39 \mu \mathrm{g} / \mathrm{L}$, repeatability $0.7 \%-2.1 \%$, reproducibility $1.7 \%-3.1 \%$, $95 \%$ percentile of normal controls $0.105 \mu \mathrm{g} / \mathrm{L}{ }^{29}$

\section{Infarct Size Quantification}

Infarct size was determined semiquantitatively by experienced neuroradiologists (E.H., C.J.M.) based on the follow-up brain imaging (mostly cranial CT) performed the day after MT (day 1 after intervention) according to a common 3-tiered scale: infarct size <1/3 MCA territory, 1/3-2/3 MCA territory, or $>2 / 3 \mathrm{MCA}$ territory or multiple vascular territories (e.g., MCA and anterior cerebral artery). ${ }^{30}$ Hemorrhagic transformation was also assessed as present or not present according National Institute of Neurological Disorders and Stroke trial criteria. ${ }^{31}$

\section{Statistical Analysis}

Statistical analyses were performed using IBM SPSS Statistics, version 22 (Statistical Package for the Social Sciences). Baseline variables and S100B values were compared between outcome groups using the $t$ test, the Mann-Whitney $U$ test, or the $\chi^{2}$ test, depending on level of measurement. Binary logistic regression analysis was used to identify independent predictors of functional outcome. Here, mRS at 90 days (0-1 vs 4-6) was included as the dependent variable, and S100B, age, sex, NIHSS at admission, NIHSS at 24 hours, mTICI, and ASPECTS were included as independent variables (see different models in the supplemental files: eTable $1 \mathrm{a} / \mathrm{b} / \mathrm{c} / \mathrm{d}$, links.lww.com/WNL/B604). A significance level of $\alpha=0.05$ was chosen for all tests.

\section{Results}

A total of 171 patients with acute ischemic with stroke were included in this study. Mean age $( \pm S D)$ was $70 \pm 14$ years, and $42 \%$ were female. On initial diagnostic angiography (CTA or MRA), MCA-M1 occlusion was documented in 128 patients, MCA-M2 occlusion in 41, anterior cerebral artery occlusion in 16, and carotid occlusion in 49 (multiple occlusions were possible). Fifty-seven percent of patients were treated with thrombolysis. Following MT, no recanalization or minimal recanalization (TICI 0-1) was achieved in 7\%, partial filling of the territory $<50 \%$ (TICI $2 \mathrm{a}$ ) in $6 \%$, partial filling $\geq 50 \%$ (TICI $2 \mathrm{~b}$ ) in $48 \%$, near complete reperfusion (TICI $2 \mathrm{c}$ ) in $2 \%$, and 
Table 1 Characteristics of the Study Population According to Dichotomized mRS Values

\begin{tabular}{|c|c|c|c|}
\hline & 3-month mRS 0-1 & 3-month mRS 2-6 & $p$ Value \\
\hline Patients, total & $60(35.5)$ & $109(64.5)$ & \\
\hline Age, y & $62.2 \pm 12.5$ & $73.8 \pm 12.5$ & $<0.001$ \\
\hline Female & $23(38.3)$ & $48(44.0)$ & NS \\
\hline \multicolumn{4}{|l|}{ Risk factors } \\
\hline Arterial hypertension & 35 (58.3) & $87(79.8)$ & \\
\hline Diabetes mellitus & 7 (11.7) & $23(21.1)$ & \\
\hline Hypercholesterolemia & $11(18.3)$ & $11(10.1)$ & \\
\hline Admission NIHSS & $12(7.0-16.0)$ & $13(9.0-17.0)$ & 0.026 \\
\hline 24 hours NIHSS & $3(1.0-5.0)$ & $12(7.0-21.0)$ & $<0.001$ \\
\hline \multicolumn{4}{|l|}{ Vessel occlusion } \\
\hline Middle cerebral artery (M1) & $45(53.6)$ & $81(55.1)$ & \\
\hline Middle cerebral artery (M2) & $15(17.9)$ & $26(17.7)$ & \\
\hline Anterior cerebral artery & $3(3.5)$ & $13(8.8)$ & \\
\hline Internal carotid artery & $21(25.0)$ & $27(18.4)$ & \\
\hline \multicolumn{4}{|l|}{ mTICl score } \\
\hline Grade 0 & $0(0)$ & $11(10.1)$ & \\
\hline Grade 1 & $0(0)$ & $0(0)$ & \\
\hline Grade $2 a$ & $1(1.7)$ & $9(8.3)$ & \\
\hline Grade $2 b$ & $31(51.7)$ & $49(45.0)$ & \\
\hline Grade $2 c$ & $2(3.3)$ & $1(0.9)$ & \\
\hline Grade 3 & $24(40.0)$ & 37 (33.9) & \\
\hline \multicolumn{4}{|l|}{ Infarct size } \\
\hline$\leq 1 / 3$ MCA territory & $45(75.0)$ & $55(50.5)$ & \\
\hline$>1 / 3$ to $<2 / 3$ MCA territory & $11(18.3)$ & $18(16.5)$ & \\
\hline$\geq 2 / 3$ MCA territory & $4(6.7)$ & $36(33.0)$ & \\
\hline ASPECTS & $9(8-10)$ & $8(7-10)$ & NS \\
\hline Hemorrhagic transformation & 7 (11.7) & $35(32.1)$ & 0.002 \\
\hline Left hemispheric ischemia & $30(50.0)$ & $48(44.0)$ & NS \\
\hline \multicolumn{4}{|l|}{ Stroke etiology } \\
\hline Cardioembolic & $18(30.0)$ & $61(56.0)$ & \\
\hline Atherothrombotic & $21(35.0)$ & $33(30.3)$ & \\
\hline Other defined & $2(3.3)$ & $2(1.8)$ & \\
\hline ESUS & 19 (31.7) & $13(11.9)$ & \\
\hline S100B, $\mu g / L$ & $0.10(0.07-0.14)$ & $0.20(0.11-0.48)$ & $<0.001$ \\
\hline
\end{tabular}


complete reperfusion in $37 \%$. When dichotomizing the functional outcome 3 months after MT, 60 patients (36\%) had a favorable outcome (mRS score $0-1$ ) and 109 patients (65\%) had an unfavorable outcome (mRS score 2-6). Two patients were unavailable for outcome assessment. Table 1 depicts further baseline variables of the study population stratified according to outcome groups.

Median S100B concentrations at day 2 after MT were lower in patients having a favorable outcome (mRS score $0-1)$ at 90 days compared to patients with an unfavorable outcome (median $0.10 \mu \mathrm{g} / \mathrm{L}$ [interquartile range (IQR) 0.07-0.14] vs $0.20 \mu \mathrm{g} / \mathrm{L}[0.11-0.48], p<0.001)$. Figure 1 depicts the steady increase of $S 100 B$ values on day 2 in parallel with poorer functional outcomes at 3 months. When stratifying for the affected side, it was apparent that in right-sided MCA infarction even larger tissue damage (in terms of S100B values) may still result in favorable mRS outcomes. In contrast, in leftsided MCA infarction, S100B values in the highest tertile predicted unfavorable outcome in $100 \%$ of cases. The distribution of mRS outcomes stratified according to S100B values and the affected side are displayed in Figure 2.

Assuming that all patients had a comparable clinical condition at study inclusion (i.e., acute ischemic stroke with LVO), as shown in Figure 3, unsuccessful recanalization always resulted in substantially elevated S100B values (in parallel with the loss of astroglial tissue). In contrast, partial (TICI 2a-c) or complete recanalization (TICI 3) resulted in both low S100B values (indicating successful recanalization with little tissue damage) and higher $\mathrm{S} 100 \mathrm{~B}$ values (indicating tissue loss despite recanalization). Similarly, Figure 4 depicts the strong correlation between S100B values and infarct size. More than $90 \%$ of patients with low S100B values have infarction size $<1 / 3$ of the MCA territory, whereas almost $90 \%$ of patients with high S100B values have at least $1 / 3$ of the MCA territory being affected. Patients with hemorrhagic transformation on follow-up imaging had higher S100B values compared to patients without hemorrhagic transformation (median $0.27 \mu \mathrm{g} / \mathrm{L}$ [IQR $0.11-0.66]$ vs $0.12 \mu \mathrm{g} / \mathrm{L}[0.08-0.24], p=$ $0.001)$.

In a multivariate logistic regression analysis, younger age (odds ratio [OR] 1.120 [confidence interval (CI) 1.068-1.175]; $p<0.001)$, lower NIHSS 24 hours after symptom onset (OR 1.233 [CI 1.107-1.374]; $p<0.001$ ), and lower S100B serum concentrations (OR 1.364 [CI $1.105-1.683] ; p=0.004)$ were independently associated with a favorable outcome after 3 months (mRS 0-1). In this model, sex, NIHSS at admission, pretreatment ASPECTS, and mTICI scores after intervention provided nonsignificant results (see supplemental files: eTable 1a-d, links.lww.com/ $\mathrm{WNL} / \mathrm{B} 604)$. When adding infarct size to this model, S100B serum concentrations did not remain an independent predictor of functional outcome (OR 1.271 [CI 1.000-1.616]; $p$ $=0.050$ ).

Figure 5 shows that patients with right-sided infarction have significant infarct sizes (in $40 \%$ of cases between $1 / 3$ and $2 / 3$ of the dependent vascular territory) despite favorable outcomes in terms of mRS. This was not observed in patients with left-sided infarctions. Here, mRS is biased due to its insensitivity for subtle right-hemispheric functional deficits and worse prognosis in patients with severe aphasia. In contrast, patients having both a favorable clinical outcome (in terms of $\mathrm{mRS}$ ) and a favorable biomarker outcome do not reveal side-different infarct sizes. In this respect, based on the distribution of $\mathrm{S} 100 \mathrm{~B}$ values at day 2, we provide the PROMETHEUS deciles (Figure 6). In individual patients, the risk for having favorable or poor functional outcome at 90 days can easily be obtained for ischemic strokes in the left and the right hemisphere.

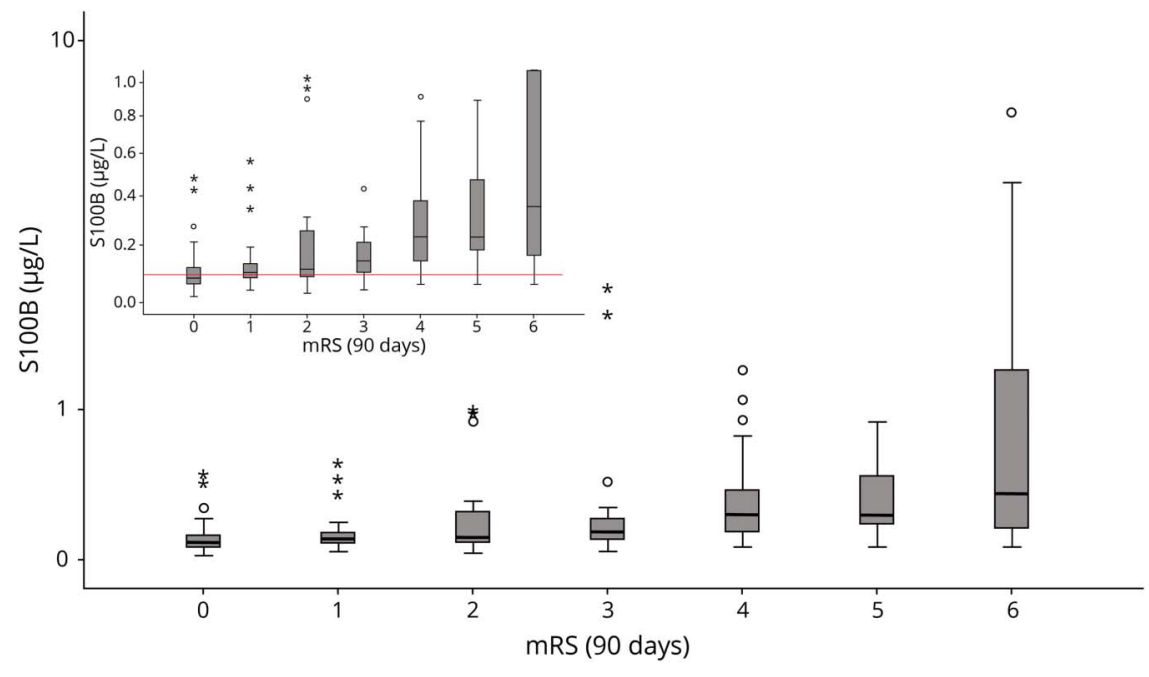

Boxplots depicting the distribution of the $\mathrm{S} 100 \mathrm{~B}$ values on day 2 stratified according to modified Rankin Scale (mRS) categories at 3 months. The box boundaries depict the 25th and 75th percentile, the line within the box indicates the median. Whiskers above and below the box mark the 90th and 10th percentiles. Outliers (1.5 - $3 \times$ interquartile range) are marked with circles; extreme values $(>3 \times$ interquartile range) are marked with asterisks. The inset shows an enlarged section of Figure 1 with a different S100B scale on the $y$-axis. The thin horizontal red line in the inset marks the upper normal range of S100B in healthy individuals. 


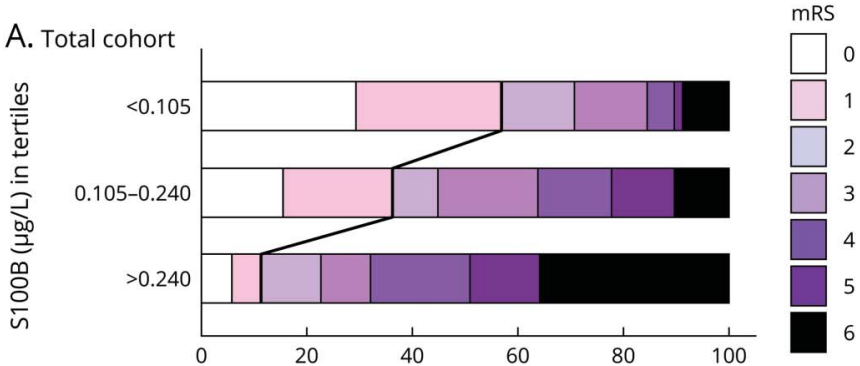

B. Left MCA

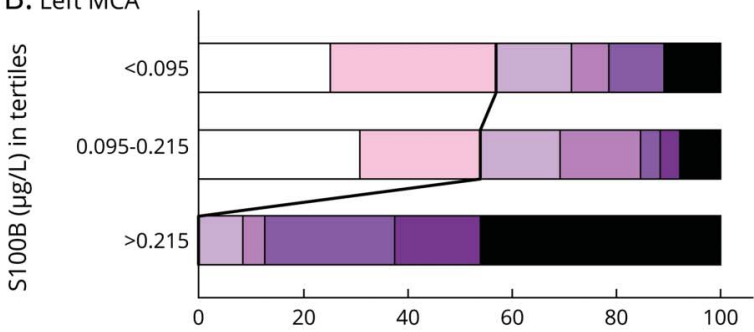

C. Right MCA

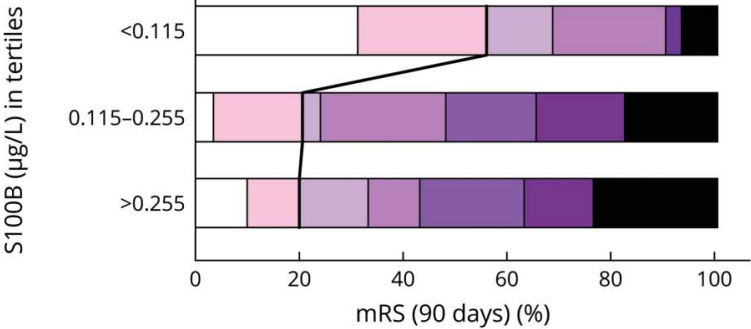

mRS

Horizontal bar graphs displaying modified Rankin Scale (mRS) grades at 3 months depending on S100B concentrations (in tertiles) for the whole cohort (A) and stratified for the left (B) and right hemisphere (C). The bold lines separate the favorable (mRS 0-1) from the unfavorable (mRS 2-6) outcome groups. An S100B value $>0.240 \mu \mathrm{g} / \mathrm{L}$ predicted an unfavorable outcome with a positive predictive value of 0.89 (sensitivity 0.43 , specificity 0.90 , negative predictive value 0.47 , overall accuracy 0.60 ). Respective values for left-sided infarctions (with S100B $>0.215 \mu \mathrm{g} / \mathrm{L}$ ) were $1.00,0.50$ $1.00,0.44$, and 0.69 and for right-sided infarctions (with S100B $>0.255 \mu \mathrm{g} /$ L) $0.80,0.39,0.80,0.39$, and 0.53. MCA = middle cerebral artery.

Ultimately, we performed internal validation of our dataset. The parallel increase of S100B levels with mRS values could be observed throughout each study year and each study center (supplemental files: eFigure 1, links.lww.com/WNL/B604).

\section{Discussion}

Our study characterized the astroglial protein S100B as a surrogate endpoint measure in patients with ischemic stroke who underwent MT. On day 2 after MT, serum concentrations of S100B provide a reliable assessment of ischemic tissue injury following LVO and subsequent therapeutic intervention. This measure is rapidly available and does not underlie biases resulting from functional hemispheric differences and other limitations that are typical for clinical outcome scales. ${ }^{5-9}$

For many years, the kinetics of S100B serum concentrations in ischemic stroke have been studied. A steady increase of S100B levels after vessel occlusion is observed, with maximum values reached 48-72 hours after symptom onset. ${ }^{14-17}$ These kinetics parallel the development of astroglial tissue damage

Figure 3 S100B Concentrations Depending on mTICI Grades

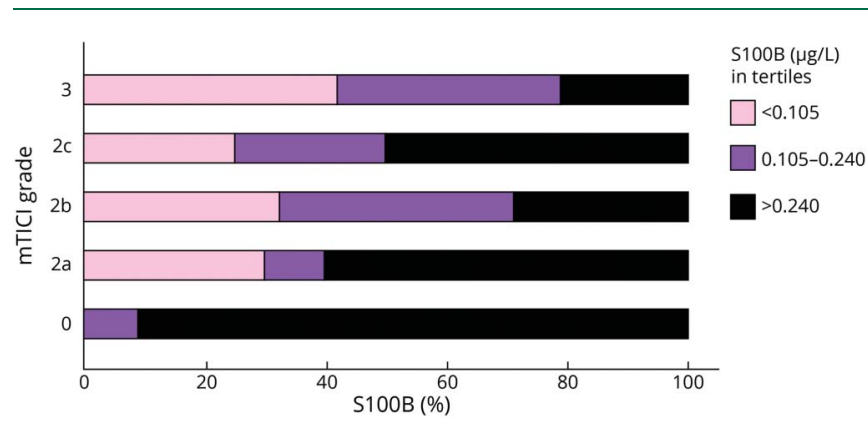

Horizontal bar graph displaying S100B concentrations (in tertiles) depending on modified Thrombolysis in Cerebral Infarction (mTICl) grades. 


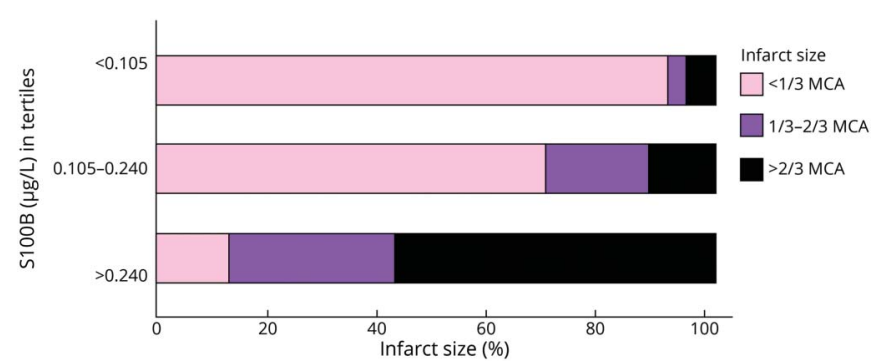

Horizontal bar graph displaying infarct size $(<1 / 3$ middle cerebral artery [MCA]; 1/3-2/3 MCA; >2/3 MCA and multiple territories) depending on $\mathrm{S} 100 \mathrm{~B}$ concentrations (in tertiles). on a cellular level (i.e., enlargement of the ischemic core). ${ }^{32}$ Associations of S100B serum elevation with malignant edema formation and blood-brain barrier damage have also been described. $^{33}$ Conversely, transient ischemia (not leading to substantial tissue injury) does not increase astroglial protein levels in serum. ${ }^{18,19}$ Thus, S100B constitutes a surrogate of the total amount of astroglial tissue involved in the ischemic core. This qualifies S100B as an interesting biomarker candidate in the context of mechanical recanalization.

According to the pathophysiology of $\mathrm{S} 100 \mathrm{~B}$ release as outlined above, we found a correlation to infarct size as determined semiquantitatively using a 3-tiered scale. Moreover, when including both infarct size and S100B into the multivariate models, the predictive value of $S 100 \mathrm{~B}$ was reduced towards nonsignificance $(p=0.05)$. This underlines the strong dependency of these 2 measures from each other. The correlation with vessel status after mechanical recanalization in terms of angiographic measures (mTICI grade) requires further reflection. On the one hand, futile recanalization always resulted in high S100B values (in parallel with the development of a significant infarct core). On the other hand, successful recanalization (mTICI 2 and below) resulted both in low S100B values (in those patients in whom the intervention prevented the development of a final infarct) and in high S100B values (in those patients who developed infarcts despite recanalization). In the latter cases, infarcts occurred due to low collateral flow or rapid growth of infarct core or significant infarct size already at the beginning of the intervention. $^{34}$

Our data underline previous findings that infarct sizes are larger in mRS $0-1$ if the stroke occurred on the right as compared to the left side. ${ }^{35}$ In the left (dominant) hemisphere, the development of infarcts frequently transfers into significant disability. ${ }^{36}$ Moreover, persisting aphasia is associated with a worse rehabilitation prognosis, limiting quality of life and reducing disability. In the right hemisphere, however, the correlation between infarct size and disability in terms of mRS is not as strong. ${ }^{36}$ We demonstrated that the application of a biomarker stratum (i.e., defining favorable outcome as mRS $0-1$ and S100B in the lowest tertile) eliminates this bias, thus providing an unbiased surrogate outcome.

Serum concentrations of S100B can be determined on routine laboratory equipment. In fact, the $\mathrm{S} 100 \mathrm{~B}$ test used here is standardized and approved for malignant melanoma diagnostics in Europe and the United States. ${ }^{29}$ Thus, the success

Figure 5 Infarct Size Depending on Dichotomized mRS at 3 Months

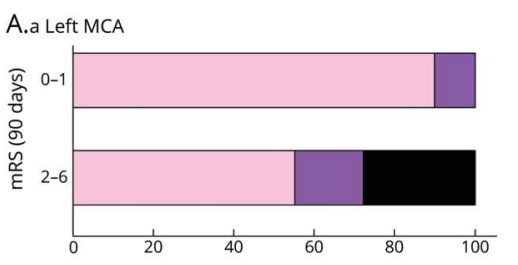

B.a Right MCA

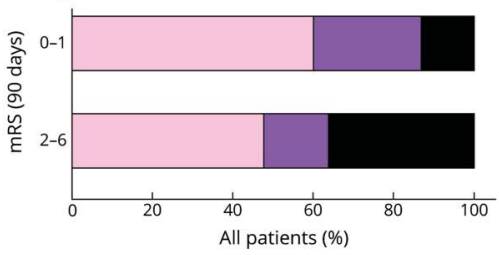

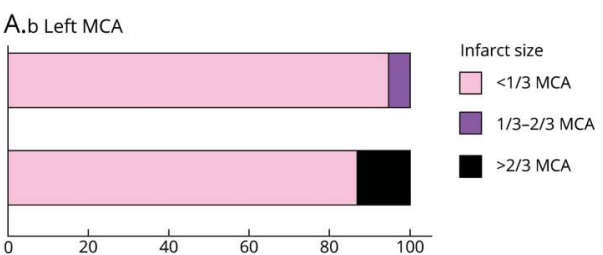

B.b Right MCA

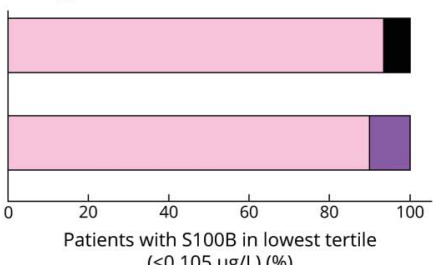

$(<0.105 \mu \mathrm{g} / \mathrm{L})(\%)$
Four horizontal bar graphs displaying infarct size (<1/3 middle cerebral artery [MCA]; 1/3-2/3 MCA; $>2 / 3$ MCA and multiple territories) depending on dichotomized modified Rankin Scale (mRS) at 3 months, stratified for the left (A) and the right (B) hemisphere, for all patients (A.a and B.a) and for the patients with $\mathrm{S} 100 \mathrm{~B}$ in the lowest tertile $(<0.105 \mu \mathrm{g} / \mathrm{L})$ (A.b and B.b). 


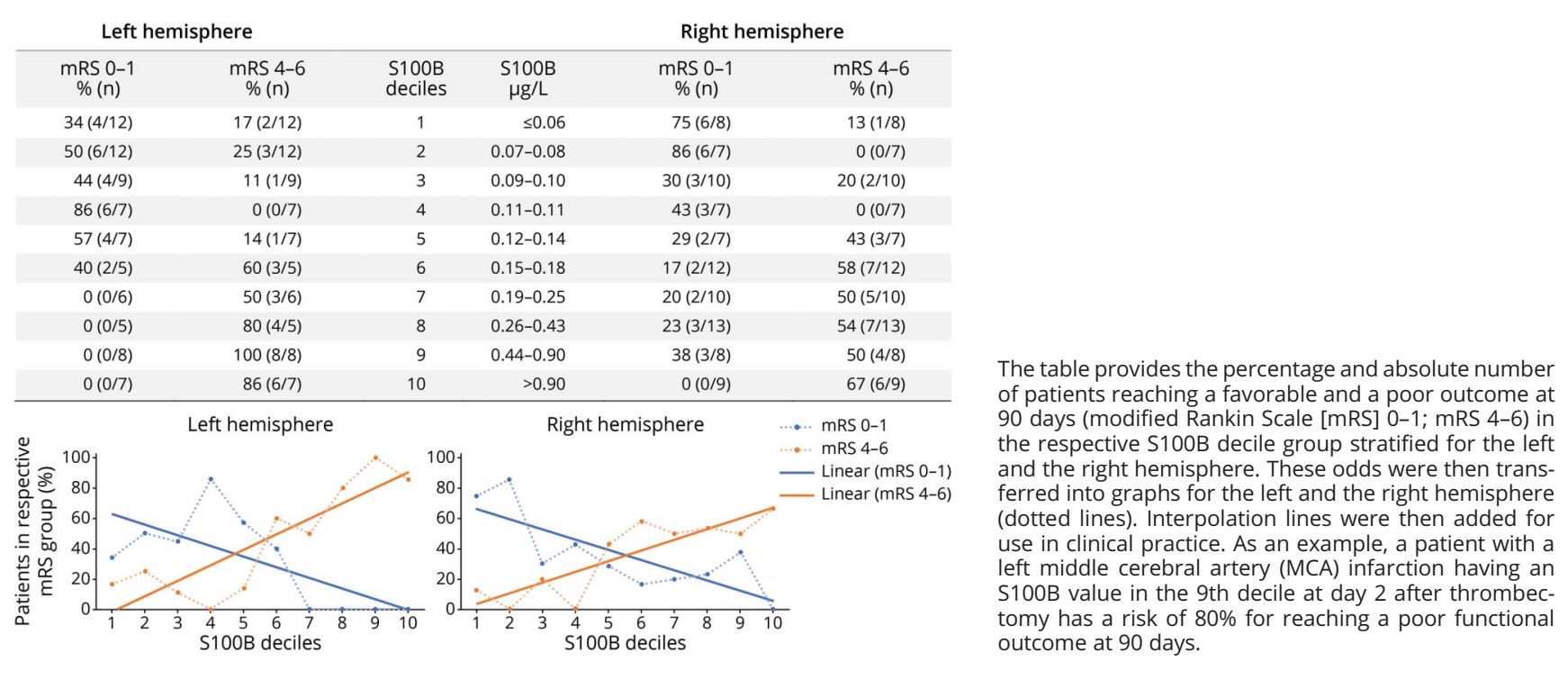

of the endovascular intervention in terms of tissue outcome can be determined easily and rapidly. Notably, routine brain imaging after MT must not be replaced by this measure, as hemorrhagic complications cannot be reliably uncovered. S100B allows outcome prediction in individual patients independent of the current clinical condition, which might be difficult to assess in early stages of disease due to ongoing functional recovery or intercurrent complications. For this reason, we provide the PROMETHEUS deciles, whose graphical presentation is designed for easy and quick application in clinical practice, to estimate the expected long-term outcome. Furthermore, S100B can be used as a surrogate endpoint measure in clinical trials. It is robust in terms of handling of blood samples, allows reliable quantification, and is much less resource-consuming in contrast to quantitative MRI analysis of infarct volumes. In addition, it allows outcome assessment independent of raters and functional scales. Nevertheless, a surrogate cannot replace patient-centered outcomes in clinical trials. Finally, in view of the internal validation of the data, it became obvious that S100B might be used as a quality assurance measure. The tissue outcome values obtained for individual patients over time can easily compared between years and between thrombectomy centers. It may help to identify factors (either prehospital or inhospital) that potentially could be optimized for better patient outcome.

As a limitation, blood samples were not taken exactly 48 hours after MT, but on day 2 after thrombectomy, which has caused some degree of heterogeneity in the time window of blood withdrawal. However, blood collection in the morning on day 2 after intervention best matches routine clinical practice. Given that the predictability of S100B in earlier time windows is limited, its use within the first hours or the first day after
EVT is likely not practicable. ${ }^{14-17}$ Here, the future combination with other brain damage markers (GFAP, neurofilament light) comes into play. At present, data quality is insufficient to draw a conclusion on any panel test. It has to be noted that only patients treated with MT were included in this study. Thus, the results are not applicable to patients with ischemic stroke in general. However, it is likely that S100B functions as an outcome indicator in a similar way. Here, future studies may evaluate broader S100B time windows, especially in patients who are not candidates for recanalizing therapies. Another limitation is the lack of an optimal gold standard of tissue damage. MRI volumetry at later time points may be one possibility, but subtle changes of brain tissue integrity after ischemic stroke ("tissue outcome") may be overlooked. Moreover, quantitative stroke volumetry was not performed within this study. Rather, infarct size was categorized on an ordinal scale by experienced radiologists on short-term follow-up imaging. The strong correlation between infarct volume and S100B serum levels has been confirmed in several studies. $^{14-17}$

S100B serum concentrations at day 2 after MT indicate the extent of ischemic tissue damage. It can be rapidly assessed independent of raters and outcome scales, thereby providing an objective surrogate outcome measure both in clinical routine and in interventional trials.

\section{Study Funding}

The authors report no targeted funding.

\section{Disclosure}

S. Luger, K. Koerbel, A. Martinez Oeckel, H. Schneider, C.J. Maurer, G. Hintereder, M. Wagner, E. Hattingen, and C. Foerch report no disclosures relevant to the manuscript. 
Outside the submitted work, C. Foerch reports personal fees from Boehringer Ingelheim and Prediction Bioscience and has a patent "Use of GFAP for identification of intracerebral hemorrhage" US20150247867 licensed to Banyan Biomarkers. Outside the submitted work, S. Luger reports consultancy fees from Sonovum GmbH. Go to Neurology.org/N for full disclosures.

\section{Publication History}

Received by Neurology January 8, 2021. Accepted in final form September 20, 2021.

\section{Appendix Authors}

\begin{tabular}{lll}
\hline Name & Location & Contribution \\
\hline Sebastian & Department of Neurology, & Major role in the acquisition \\
Luger, MD & $\begin{array}{l}\text { University Hospital Frankfurt } \\
\text { / Goethe University }\end{array}$ & $\begin{array}{l}\text { of data; designed and } \\
\text { conceptualized the study; } \\
\text { analyzed and interpreted the } \\
\text { data; drafted the manuscript } \\
\text { frankfurt, Germany }\end{array}$ \\
& & for intellectual content
\end{tabular}

\begin{tabular}{|c|c|c|}
\hline $\begin{array}{l}\text { Kimberly } \\
\text { Koerbel, MD }\end{array}$ & $\begin{array}{l}\text { Department of Neurology, } \\
\text { University Hospital Frankfurt } \\
\text { / Goethe University } \\
\text { Frankfurt, Germany }\end{array}$ & $\begin{array}{l}\text { Acquisition of data; analyzed } \\
\text { and interpreted the data; } \\
\text { revised the manuscript for } \\
\text { intellectual content }\end{array}$ \\
\hline $\begin{array}{l}\text { Ariane } \\
\text { Martinez } \\
\text { Oeckel, MD }\end{array}$ & $\begin{array}{l}\text { Department of Neurology, } \\
\text { University Hospital Frankfurt } \\
\text { / Goethe University } \\
\text { Frankfurt, Germany }\end{array}$ & $\begin{array}{l}\text { Acquisition of data; analyzed } \\
\text { and interpreted the data; } \\
\text { revised the manuscript for } \\
\text { intellectual content }\end{array}$ \\
\hline $\begin{array}{l}\text { Hauke } \\
\text { Schneider, } \\
\text { MD, MBA }\end{array}$ & $\begin{array}{l}\text { Department of Neurology, } \\
\text { University Hospital } \\
\text { Augsburg, Germany }\end{array}$ & $\begin{array}{l}\text { Acquisition of data; revised } \\
\text { the manuscript for } \\
\text { intellectual content }\end{array}$ \\
\hline $\begin{array}{l}\text { Christoph J. } \\
\text { Maurer, MD }\end{array}$ & $\begin{array}{l}\text { Department of Diagnostic } \\
\text { and Interventional Radiology } \\
\text { and Neuroradiology, } \\
\text { University Hospital } \\
\text { Augsburg, Germany }\end{array}$ & $\begin{array}{l}\text { Acquisition of data; revised } \\
\text { the manuscript for } \\
\text { intellectual content }\end{array}$ \\
\hline $\begin{array}{l}\text { Gudrun } \\
\text { Hintereder, } \\
\text { MD }\end{array}$ & $\begin{array}{l}\text { Central Laboratory, } \\
\text { University Hospital Frankfurt, } \\
\text { Germany }\end{array}$ & $\begin{array}{l}\text { Supervised and coordinated } \\
\text { laboratory measurements; } \\
\text { revised the manuscript for } \\
\text { intellectual content }\end{array}$ \\
\hline $\begin{array}{l}\text { Marlies } \\
\text { Wagner, MD }\end{array}$ & $\begin{array}{l}\text { Institute of Neuroradiology, } \\
\text { University Hospital Frankfurt } \\
\text { / Goethe University } \\
\text { Frankfurt, Germany }\end{array}$ & $\begin{array}{l}\text { Revised the manuscript for } \\
\text { intellectual content }\end{array}$ \\
\hline $\begin{array}{l}\text { Elke } \\
\text { Hattingen, } \\
\text { MD }\end{array}$ & $\begin{array}{l}\text { Institute of Neuroradiology, } \\
\text { University Hospital Frankfurt } \\
\text { / Goethe University } \\
\text { Frankfurt, Germany }\end{array}$ & $\begin{array}{l}\text { Acquisition of data; revised } \\
\text { the manuscript for } \\
\text { intellectual content }\end{array}$ \\
\hline $\begin{array}{l}\text { Christian } \\
\text { Foerch, MD }\end{array}$ & $\begin{array}{l}\text { Department of Neurology, } \\
\text { University Hospital Frankfurt } \\
\text { / Goethe University } \\
\text { Frankfurt, Germany }\end{array}$ & $\begin{array}{l}\text { Designed and } \\
\text { conceptualized the study; } \\
\text { analyzed and interpreted the } \\
\text { data; drafted the manuscript } \\
\text { for intellectual content }\end{array}$ \\
\hline
\end{tabular}

\section{References}

1. Goyal M, Menon BK, van Zwam WH, et al. Endovascular thrombectomy after largevessel ischaemic stroke: a meta-analysis of individual patient data from five randomised trials. Lancet. 2016;387(10029):1723-1731.

2. Schellinger PD, Demaerschalk BM. Endovascular stroke therapy in the late time window. Stroke. 2018;49(10):2559-2561.

3. Duncan PW, Jorgensen HS, Wade DT. Outcome measures in acute stroke trials: a systematic review and some recommendations to improve practice. Stroke. 2000; 31(6):1429-1438.
4. Rankin J. Cerebral vascular accidents in patients over the age of 60: II: prognosis. Scott Med J. 1957;2(5):200-215.

5. Quinn TJ, Dawson J, Walters MR, Lees KR. Exploring the reliability of the modified Rankin Scale. Stroke. 2009;40(3):762-766.

6. Saver JL, Filip B, Hamilton S, et al. Improving the reliability of stroke disability grading in clinical trials and clinical practice: the Rankin Focused Assessment (RFA). Stroke. 2010;41(5):992-995

7. Wilson JT, Hareendran A, Grant M, et al. Improving the assessment of outcomes in stroke: use of a structured interview to assign grades on the modified Rankin Scale. Stroke. 2002;33(9):2243-2246.

8. Cheng B, Forkert ND, Zavaglia M, et al. Influence of stroke infarct location on functional outcome measured by the modified Rankin Scale. Stroke. 2014;45(6): 1695-1702.

9. Ernst M, Boers AMM, Forkert ND, et al. Impact of ischemic lesion location on the $\mathrm{mRS}$ score in patients with ischemic stroke: a voxel-based approach. AJNR Am J Neuroradiol. 2018;39(11):1989-1994.

10. Di Monaco M, Schintu S, Dotta M, Barba S, Tappero R, Gindri P. Severity of unilateral spatial neglect is an independent predictor of functional outcome after acute inpatient rehabilitation in individuals with right hemispheric stroke. Arch Phys Med Rehabil. 2011;92(8):1250-1256.

11. Stein MS, Kilbride C, Reynolds FA. What are the functional outcomes of right hemisphere stroke patients with or without hemi-inattention complications? A critical narrative review and suggestions for further research. Disabil Rehabil. 2016;38(4): 315-328.

12. Saver JL. Optimal end points for acute stroke therapy trials: best ways to measure treatment effects of drugs and devices. Stroke. 2011;42(8):2356-2362.

13. Puntonet J, Richard ME, Edjlali M, et al. Imaging findings after mechanical thrombectomy in acute ischemic stroke. Stroke. 2019;50(6):1618-1625.

14. Buttner T, Weyers S, Postert T, Sprengelmeyer R, Kuhn W. S-100 protein: serum marker of focal brain damage after ischemic territorial MCA infarction. Stroke. 1997; 28(10):1961-1965.

15. Foerch C, Singer OC, Neumann-Haefelin T, du Mesnil de Rochemont R, Steinmetz H, Sitzer M. Evaluation of serum S100B as a surrogate marker for long-term outcome and infarct volume in acute middle cerebral artery infarction. Arch Neurol. 2005;62(7):1130-1134.

16. Herrmann M, Vos P, Wunderlich MT, de Bruijn $\mathrm{CH}$, Lamers $\mathrm{KJ}$. Release of glial tissue-specific proteins after acute stroke: a comparative analysis of serum concentrations of protein S-100B and glial fibrillary acidic protein. Stroke. 2000;31(11): 2670-2677.

17. Missler U, Wiesmann M, Friedrich C, Kaps M. S-100 protein and neuron-specific enolase concentrations in blood as indicators of infarction volume and prognosis in acute ischemic stroke. Stroke. 1997;28(10):1956-1960.

18. Foerch C, du Mesnil de Rochemont R, Singer O, et al. S100B as a surrogate marker for successful clot lysis in hyperacute middle cerebral artery occlusion. J Neurol Neurosurg Psychiatry. 2003;74(3):322-325.

19. Wunderlich MT, Wallesch CW, Goertler M. Release of glial fibrillary acidic protein is related to the neurovascular status in acute ischemic stroke. Eur J Neurol. 2006; 13(10):1118-1123.

20. Kowoll CM, Dohmen C, Kahmann J, et al. Standards of scoring, monitoring, and parameter targeting in German neurocritical care units: a national survey. Neurocrit Care. 2014;20(2):176-186.

21. von Elm E, Altman DG, Egger M, et al. The Strengthening the Reporting of Observational Studies in Epidemiology (STROBE) statement: guidelines for reporting observational studies. PLoS Med. 2007;4(10):e296.

22. Powers WJ, Rabinstein AA, Ackerson T, et al. Guidelines for the early management of patients with acute ischemic stroke: 2019 update to the 2018 guidelines for the early management of acute ischemic stroke: a guideline for Healthcare Professionals from the American Heart Association/American Stroke Association. Stroke. 2019;50(12): e344-e418.

23. Goyal A, Failla MD, Niyonkuru C, et al. $\mathrm{S} 100 \mathrm{~b}$ as a prognostic biomarker in outcome prediction for patients with severe traumatic brain injury. J Neurotrauma. 2013; 30(11):946-957.

24. Harpio R, Einarsson R. S100 proteins as cancer biomarkers with focus on S100B in malignant melanoma. Clin Biochem. 2004;37(7):512-518.

25. Zaidat OO, Yoo AJ, Khatri $\mathrm{P}$, et al. Recommendations on angiographic revascularization grading standards for acute ischemic stroke: a consensus statement. Stroke. 2013;44(9):2650-2663.

26. Adams HP Jr, Bendixen BH, Kappelle LJ, et al. Classification of subtype of acute ischemic stroke: definitions for use in a multicenter clinical trial: TOAST: Trial of Org 10172 in Acute Stroke Treatment. Stroke. 1993;24(1):35-41.

27. Janssen PM, Visser NA, Dorhout Mees SM, Klijn CJ, Algra A, Rinkel GJ. Comparison of telephone and face-to-face assessment of the modified Rankin Scale. Cerebrovasc Dis. 2010;29(2):137-139.

28. Mussack T, Kirchhoff C, Buhmann S, et al. Significance of Elecsys S100 immunoassay for real-time assessment of traumatic brain damage in multiple trauma patients. Clin Chem Lab Med. 2006;44(9):1140-1145.

29. Roche. diagnostics.roche.com.

30. Kalafut MA, Schriger DL, Saver JL, Starkman S. Detection of early CT signs of $>1 / 3$ middle cerebral artery infarctions: interrater reliability and sensitivity of CT interpretation by physicians involved in acute stroke care. Stroke. 2000;31(7):1667-1671.

31. Yaghi S, Willey JZ, Cucchiara B, et al. Treatment and outcome of hemorrhagic transformation after intravenous alteplase in acute ischemic stroke: a scientific statement for Healthcare Professionals from the American Heart Association/ American Stroke Association. Stroke. 2017;48(12):e343-e361. 
32. Brunkhorst R, Pfeilschifter W, Foerch C. Astroglial proteins as diagnostic markers of acute intracerebral hemorrhage-pathophysiological background and clinical findings. Transl Stroke Res. 2010;1(4):246-251.

33. Foerch C, Otto B, Singer OC, et al. Serum S100B predicts a malignant course of infarction in patients with acute middle cerebral artery occlusion. Stroke. 2004;35(9): 2160-2164.
34. Liebeskind DS. Recanalization and reperfusion in acute ischemic stroke. F1000 Med Rep. 2010;2:71.

35. Foerch C, Misselwitz B, Sitzer M, et al. Difference in recognition of right and left hemispheric stroke. Lancet. 2005;366(9483):392-393.

36. Etherton MR, Rost NS, Wu O. Infarct topography and functional outcomes. J Cereb Blood Flow Metab. 2018;38(9):1517-1532. 


\section{Neurology}

\section{Role of S100B Serum Concentration as a Surrogate Outcome Parameter After Mechanical Thrombectomy \\ Sebastian Luger, Kimberly Koerbel, Ariane Martinez Oeckel, et al.}

Neurology 2021;97;e2185-e2194 Published Online before print October 11, 2021

DOI 10.1212/WNL.0000000000012918

\section{This information is current as of October 11, 2021}

\section{Updated Information \&} Services

References

Subspecialty Collections

Permissions \& Licensing

Reprints including high resolution figures, can be found at: http://n.neurology.org/content/97/22/e2185.full

This article cites 35 articles, 16 of which you can access for free at: http://n.neurology.org/content/97/22/e2185.full\#ref-list-1

This article, along with others on similar topics, appears in the following collection(s):

All Cerebrovascular disease/Stroke

http://n.neurology.org/cgi/collection/all_cerebrovascular_disease_strok $\mathrm{e}$

\section{Infarction}

http://n.neurology.org/cgi/collection/infarction

Information about reproducing this article in parts (figures,tables) or in its entirety can be found online at:

http://www.neurology.org/about/about_the_journal\#permissions

Information about ordering reprints can be found online:

http://n.neurology.org/subscribers/advertise

Neurology ${ }^{\circledR}$ is the official journal of the American Academy of Neurology. Published continuously since 1951, it is now a weekly with 48 issues per year. Copyright Copyright ( 2021 The Author(s). Published by Wolters Kluwer Health, Inc. on behalf of the American Academy of Neurology.. All rights reserved. Print ISSN: 0028-3878. Online ISSN: 1526-632X.

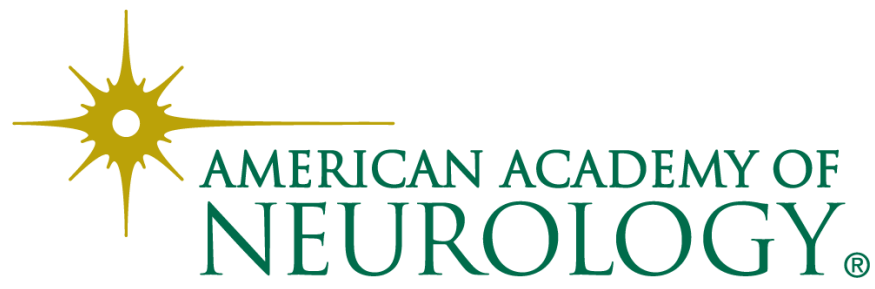

